\title{
The Influence of Embedding Different Loadings of MWCNTs on the Structure and Permeation of CAB Blended Membrane
}

\author{
Anas Khalid Abdelsalam Abdelgadir, ${ }^{1}$ Zeinab Abbas Jawad, ${ }^{1 *}$ \\ Peng Chee Tan ${ }^{2}$ and Siaw Khur Wee
}

\begin{abstract}
${ }^{1}$ School of Engineering and Science, Department of Chemical Engineering, Curtin University Malaysia, CDT 250, 98009 Miri, Sarawak, Malaysia ${ }^{2}$ School of Energy and Chemical Engineering, Xiamen University Malaysia, Jalan Sunsuria, Bandar Sunsuria, 43900 Sepang, Selangor, Malaysia

${ }^{3}$ Department of Petroleum Engineering, Faculty of Engineering and Science, Curtin University Malaysia, CDT 250, 98009 Miri, Sarawak, Malaysia
\end{abstract}

*Corresponding author: zeinab.aj@curtin.edu.my

Published online: 25 April 2020

To cite this article: Abdelgadir, A. K. A. et al. (2020). The influence of embedding different loadings of MWCNTs on the structure and permeation of CAB blended membrane. J. Phys. Sci., 31(1), 15-36. https://doi.org/10.21315/jps2020.31.1.2

To link to this article: https://doi.org/10.21315/jps2020.31.1.2

\begin{abstract}
Carbon dioxide $\left(\mathrm{CO}_{2}\right)$ has been widely known to be the main contributor to global warming and temperature fluctuations. The $\mathrm{CO}_{2}$ gas is primarily found in the combustion of fossil fuels and natural gases. Several approaches were considered in the industry to minimise $\mathrm{CO}_{2}$ emissions such as ammonia scrubbing and membrane technology. In recent years, membrane technology has exhibited excellent $\mathrm{CO}_{2}$ separation performance especially the mixed matrix membrane (MMM) due to its combined properties of organic and inorganic materials. The small footprint and high efficiency of the membrane technology compared with the traditional gas separation processes has given it a distinct advantage. In this work, the MMMs are synthesised from the cellulose acetate butyrate (CAB) polymer and the functionalised multi-walled carbon nanotubes (MWCNTs) through Chen's soft-cutting method. This study aims to synthesise an excellent MMM with high separation performance by studying the effects of incorporating different amounts of MWCNTs fillers into the CAB blended membrane. The fabricated MMM was developed using 4 wt\% of $C A B$ with molecular weights of 12000, 65000 and 70000 mixed in a ratio of 1:1:1. The functionalised MWCNTs were incorporated into the CAB matrix with different filler loadings ranging from $0.0125 \mathrm{wt} \%$ to $0.2 \mathrm{wt} \%$. The separation performance of the fabricated MMM was successfully conducted towards $\mathrm{CO}_{2} / \mathrm{N}_{2}$ separation. The highest $\mathrm{CO}_{2}$ and $\mathrm{N}_{2}$ gas permeance were exhibited from the MMM-0.025 with average values of $36.0 \pm 0.4 \mathrm{GPU}$ and $28.0 \pm 0.2 \mathrm{GPU}$, respectively. Further, the highest $\mathrm{CO}_{2} / \mathrm{N}_{2}$ selectivity
\end{abstract}


exhibited from the MMM-0.025 was $1.3 \pm 0.1$. The outcome of this research confirmed the positive effects of different $\mathrm{Mn}$ and MWCNTs filler amounts on the performance of the MMM.

Keywords: Cellulose acetate butyrate, multi-walled carbon nanotubes, MWCNTs, mixed matrix membrane, gas permeation test

\section{INTRODUCTION}

One of the major issues concerning the international community in recent years is the increase of greenhouse gas emissions into the atmosphere, particularly carbon dioxide $\left(\mathrm{CO}_{2}\right)$. The combustion process of natural gases and fossil fuels is the primary source for $\mathrm{CO}_{2}$ emissions. ${ }^{1}$ The global temperature is expected to increase by $3^{\circ} \mathrm{C}$ by the year $2050 .^{2}$ The increase in $\mathrm{CO}_{2}$ will cause negative consequences such as changes in the ecosystems and rising sea levels. Numerous technologies have been listed as potential candidates for $\mathrm{CO}_{2}$ gas separation process such as amine-based absorption, cryogenic fractionation and membrane technology. ${ }^{3}$ However, besides the small footprint of the membrane technology, its high efficiency and low cost makes it a preferable choice over the other technologies for the $\mathrm{CO}_{2}$ separation process. ${ }^{1}$

Several materials were used to manufacture and fabricate the membrane, such as organic, inorganic and biological materials. However, $90 \%$ of the total membranes installed today are made of nine polymer organic materials such as polysulfone, polyaramide, poly(vinylidene chloride) (PVDC), poly(furfuryl alcohol) (PEA), polyacrylonitrite (PAN), phenolic resins, poly (phenylene oxide), cellulose acetate (CA) and cellulose acetate butyrate (CAB). These materials have a tendency of producing membranes with high permeability and selectivity. ${ }^{3}$ With reference to the CAB membrane, it was first communalised in 1938. The excellent film-building properties of the $\mathrm{CAB}$ polymer makes it a suitable choice for membrane-forming. In addition, the existence of the butyl groups in the $\mathrm{CAB}$ polymer has the ability to resist impact, weather conditions and chemicals exposure. ${ }^{4}$ However, it has been proven that the polymer-based membrane suffers a trade-off relationship between permeability and selectivity in terms of its separation performance. ${ }^{5}$ On the other hand, the inorganic membranes have high thermal and chemical stability of the inorganic materials in addition to greater selectivity as compared to the polymeric membranes, thus, making them desired materials to investigate. ${ }^{6}$ Inorganic membranes such as zeolites, carbon molecular sieve, graphene and carbon nanotubes (CNTs) exhibit high selectivity and ability to resist harsh industrial conditions. ${ }^{7}$ However, the inorganic membranes are expensive to produce, and consist of brittle structures. Therefore, to eliminate the limitations of the inorganic and polymeric materials, the approach of combining both the properties of the 
materials was accomplished by the mixed matrix membrane (MMM). ${ }^{8}$ The MMM was designed to inherit the superior properties of the inorganic materials, and cost effectiveness and high efficiency of the polymeric materials. ${ }^{7}$ The gas separation performance of the MMMs was improved by integrating the CNTs filler in the polymer membrane. The single-walled CNTs (SWCNTs) and multi-walled CNTs (MWCNTs) provided high efficiency and high stability membranes with low cost and rigid structures. Several studies have been conducted to investigate the gas separation performance of the MWCNTs within the MMM structure. ${ }^{5}$ Murali et al. studied the effect of adding MWCNTs to the gas permeation properties of hydrogen $\left(\mathrm{H}_{2}\right)$, nitrogen $\left(\mathrm{N}_{2}\right)$, oxygen $\left(\mathrm{O}_{2}\right)$ and $\mathrm{CO}_{2}$ gases in the Pebax-1657 membranes by controlling the loadings of the MWCNTs. Based on their study, the incorporation of MWCNTs led to a noticeable increase in the membrane free volume. ${ }^{9}$

Thus, the aim of this work is to prepare a new MMM from the CAB polymer and MWCNTs fillers with high permeance of $\mathrm{CO}_{2}$ and $\mathrm{CO}_{2} / \mathrm{N}_{2}$ selectivity. Up to date, no studies have been conducted to investigate the influence of blending equal ratios of the polar acetyl group of $16-19 \mathrm{wt} \%, 28-31 \mathrm{wt} \%$ and $12-15 \mathrm{wt} \%$ for $\mathrm{CAB}$ molecular weights of 12000, 65000 and 70000, respectively, on the non-polar $\mathrm{CO}_{2} / \mathrm{N}_{2}$ separation. Furthermore, different MWCNTs filler amounts of $0.0125 \mathrm{wt} \%, 0.025 \mathrm{wt} \%, 0.1 \mathrm{wt} \%$ and $0.2 \mathrm{wt} \%$ were integrated within the $\mathrm{CAB}$ polymeric membrane in order to improve and further increase the efficiency of the MMM towards $\mathrm{CO}_{2} / \mathrm{N}_{2}$ separation.

\section{EXPERIMENTAL}

\subsection{Materials}

CAB with polymer molecular weights of 12000,65000 and 70000 was purchased from Sigma-Aldrich (Malaysia) for membrane fabrication. MWCNTs with average outer and inner diameters of $27.00 \mathrm{~mm}$ and $8.85 \mathrm{~mm}$ respectively, were purchased from Shenzhen Nanotech Port Co. Ltd., China. The solvent chloroform (99.7\%) was purchased from Merck (Malaysia). The hexane (99.8\%) and isopropyl alcohol (99.6\%) were supplied by Merck (Malaysia) for membrane drying. The betacyclodextrin $(\beta-C D)$ and ethanol solutions acquired from Merck (Malaysia) were used to functionalise the MWCNTs.

\subsection{Fabrication of CAB Membrane}

The phase inversion method was used to form the neat $\mathrm{CAB}$ membrane. The experiment was set up by preparing a solution consisting of $4 \mathrm{wt} \%$ of $\mathrm{CAB}$ and $96 \mathrm{wt} \%$ of chloroform. ${ }^{10}$ The $4 \mathrm{wt} \%$ was taken from the $\mathrm{CAB}$ with molecular 
weights of 12000,65000 and 70000 in ratios of 1:1:1. The prepared solution was then stirred for $24 \mathrm{~h}$ before sonicated for $20 \mathrm{~min}$. The sonication process is important to even out the surface of the membrane layer by removing the air bubbles on the membrane surface. ${ }^{10}$ A casting machine known as the automatic applicator was then utilised to cast the membrane layer in a glass plate to a thickness of $250 \mu \mathrm{m}$. The solvent was then exposed to evaporation under a temperature of $25^{\circ} \mathrm{C}$ for a period of $5 \mathrm{~min} .{ }^{4}$ To eliminate the residual solvent, the membrane was then immersed in distilled water of $22^{\circ} \mathrm{C}$ for a period of $24 \mathrm{~h}$. The membrane formed was subsequently dried by using isopropyl alcohol and hexane. The membrane was first immersed in isopropyl alcohol for $1 \mathrm{~h}$ followed by hexane for another $1 \mathrm{~h}$.

The formed membrane was consequently left to dry in an oven at $70^{\circ} \mathrm{C}$ between two glass panels for $24 \mathrm{~h}$ in order to eliminate all the excess solvents. The dried membrane was then stored in a desiccator. ${ }^{11}$

\subsection{Functionalisation of MWCNTs}

The functionalisation process was started by drying the MWCNTs in an oven at $120^{\circ} \mathrm{C}$ for a period of approximately $8 \mathrm{~h} .{ }^{12}$ The dried MWCNTs were then functionalised by using Chen's soft-cutting method. In this method, the MWCNTs along with the $\beta-C D$ with a concentration ratio of $1.30 \mathrm{wt} \%$ were then grounded by using an agate mortar and pestle. In order to obtain a sticky and greyish texture of the mixture, ethanol was added gradually for a period of $10 \mathrm{~min} .{ }^{13}$ The mixture was then left to settle for an additional $2.5 \mathrm{~h}$ to obtain a fine grey powder, which was then left in the oven for $24 \mathrm{~h}$. The temperature of the oven was set at $80^{\circ} \mathrm{C} .{ }^{13}$

\subsection{Fabrication of MMM}

The MMM was prepared by mixing the MWCNTs with a specific amount of chloroform. The solvent mixer was then sonicated for $20 \mathrm{~min}$ to remove the air bubbles from the membrane surface. ${ }^{14}$ In order to obtain better particle distribution of the MWCNTs, the mixer was stirred for a period of $4 \mathrm{~h} .{ }^{15} \mathrm{~A}$ certain amount of the CAB was then added to the mixer and stirred for $24 \mathrm{~h} .{ }^{13}$ The composition of the fabricated MMM is represented in Table 1.

\subsection{Membrane Permeation Test}

Before conducting the gas permeation test, the membrane layer formed was experimented in order to ensure the reliability and accuracy of the experiment results. Initially, the membrane film was cut into a circular shape, placed on top of the membrane cell, and covered tightly. 
Table 1: The composition of the fabricated MMM.

\begin{tabular}{lclcccc}
\hline \multicolumn{3}{c}{ MWCNTs-F (wt\%) } & $\begin{array}{c}\text { CAB } \\
\text { polymer } \\
(\mathrm{wt} \%)\end{array}$ & $\begin{array}{c}\text { Chloroform } \\
(\mathrm{wt} \%)\end{array}$ & $\begin{array}{c}\text { Casting } \\
\text { thickness } \\
(\mu \mathrm{m})\end{array}$ & $\begin{array}{c}\text { Sample } \\
\text { description }\end{array}$ \\
\hline $\begin{array}{c}\text { Total filler } \\
(\mathrm{wt} \%)\end{array}$ & $\begin{array}{c}\text { MWCNTs } \\
(\mathrm{g})\end{array}$ & $\beta-\mathrm{CD}$ & 4.0 & 64.00 & 250 & CAB-M \\
0.0 & 0.00 & 0.00 & 4.0 & 64.34 & 250 & MMM-P \\
0.1 & 0.1280 & 0.00 & 4.0 & 64.42 & 250 & MMM-0.0125F \\
0.0125 & 0.0156 & 0.468 & 4.0 & 64.38 & 250 & MMM-0.025F \\
0.025 & 0.0322 & 0.966 & 4.0 & 64.34 & 250 & MMM-0.1F \\
0.1 & 0.1280 & 3.84 & 4.0 & 64.25 & 250 & MMM-0.2F \\
0.2 & 0.2644 & 7.932 & 4.0 & & &
\end{tabular}

A leak detection test was then conducted on the membrane layer to avoid any leaks during the gas permeation experiment. The volume displacement in conjunction with the soap bubble flow meter was used to measure the flow rate of permeate and retentate independently. The gas permeation test was conducted at room temperature by using purified $\mathrm{CO}_{2}$ and $\mathrm{N}_{2}$ gases. The test was started by adjusting the inlet gas $\left(\mathrm{CO}_{2}\right.$ or $\left.\mathrm{N}_{2}\right)$ flow rate released from the gas cylinder at $100 \mathrm{ml} \mathrm{min}{ }^{-1}$ by using a mass flow controller, which was connected to a two-channel digital set point unit. The fabricated membrane was cut in a round shape with an effective area of $7.025 \mathrm{~cm}^{2}$ to fit the porous stainless-steel cell. After that, the gas $\left(\mathrm{CO}_{2}\right.$ or $\mathrm{N}_{2}$ ) was introduced to the stainless-steel membrane cell at a pressure of 0.5 bars to 3 bars. The gas permeation experiment set-up is presented in Figure 1.

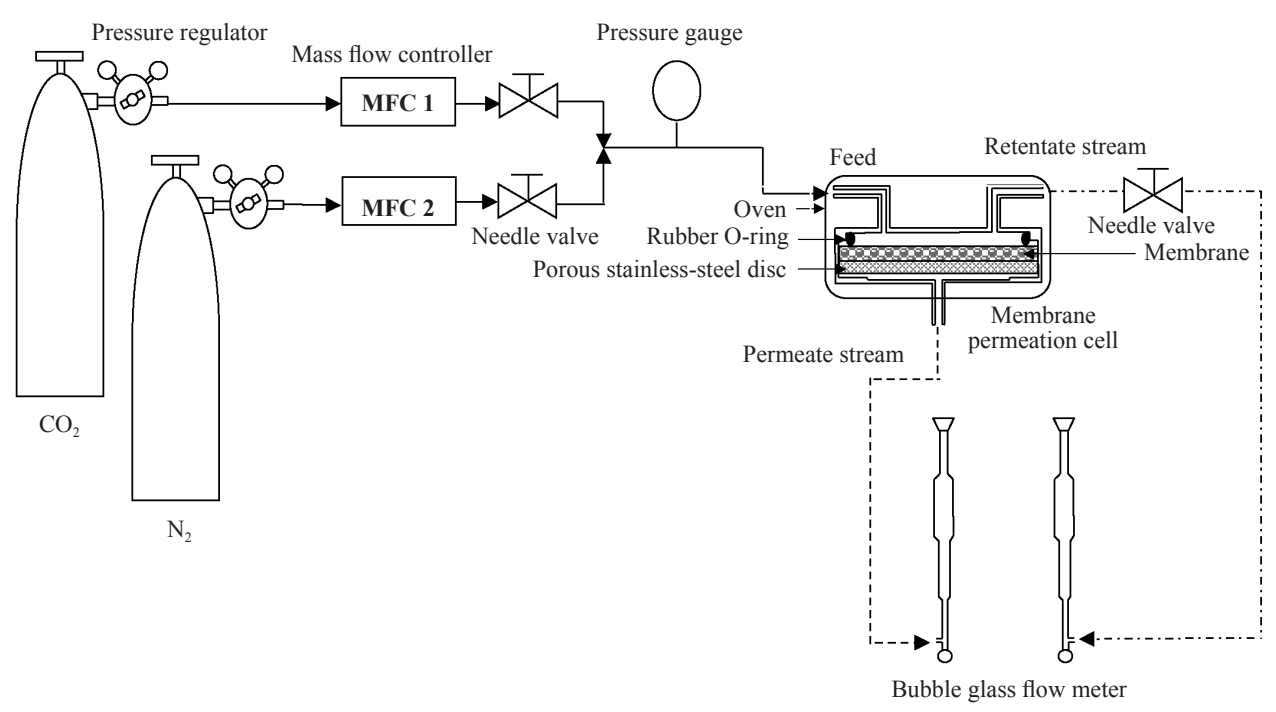

Figure 1: The gas permeation experimental set-up. 
The performance of the gas permeation and separation was obtained by the following calculations.

The flux of gas is obtained by the equation:

$$
\mathrm{N}_{\mathrm{i}}=\frac{\text { mol of component gas A permeate through the membrane }}{\mathrm{tA}_{\mathrm{m}}}
$$

where $\mathrm{N}_{\mathrm{i}}=$ flux of gas $\left(\frac{\mathrm{mol}}{\mathrm{m}^{2}} \cdot \mathrm{s}\right), \mathrm{t}=$ time $(\mathrm{s}), \mathrm{A}_{\mathrm{m}}=$ area $\left(\mathrm{m}^{2}\right)$ and $\mathrm{i}=$ the type of gas tested $\left(\mathrm{CO}_{2}\right.$ or $\left.\mathrm{N}_{2}\right)$.

The permeability of the gas equation is represented by the following:

$$
P_{i}=\frac{N i}{\Delta p_{i}}
$$

where $P_{i}=$ permeability of the membrane gas $\left(\frac{\mathrm{mol}}{\mathrm{m}^{2}} \cdot \mathrm{s} \cdot \mathrm{Pa}\right), \Delta p_{i}=$ the pressure difference across the membrane $(\mathrm{Pa})$, and $\mathrm{A}_{\mathrm{m}}=\operatorname{area}\left(\mathrm{m}^{2}\right)$.

Meanwhile, the permeance of the membrane is which is noted by $(\mathrm{P} / l)$ can be obtained by the following equation: ${ }^{16}$

$$
\frac{\mathrm{P}}{l}=\frac{\mathrm{Q}}{A \Delta \mathrm{P}}
$$

where $\frac{\mathrm{P}}{l}=$ the permeance of the membrane (GPU, in which 1 GPU $=1 \times 10^{-6}$ $\left(\mathrm{cm}^{3}(\mathrm{STP}) /\left(\mathrm{cm}^{2} . \mathrm{s} . \mathrm{cmHg}\right)\right), \mathrm{Q}=$ the flowrate indicated by flowmeter $\left(\mathrm{cm}^{3} \mathrm{~s}^{-1}\right)$, $l=$ The membrane thickness $(\mu \mathrm{m})$, and $\Delta \mathrm{P}=$ the pressure difference in the membrane permeation cell (cmHg).

The ratio of permeability of $\mathrm{CO}_{2} / \mathrm{N}_{2}$ (selectivity of the membrane) is represented by the following equation using the ideal separation factor $\left(\alpha_{i j}\right):{ }^{17}$

$$
\alpha_{i j}=\frac{P_{i}}{P_{j}}=\frac{P_{i / l}}{P_{j / l}}
$$

\subsection{Transport Phenomena in Asymmetric Membranes}

\subsubsection{Solution diffusion mechanism}

Solution diffusion mechanism is the most commonly used model for permeation in the asymmetric membrane. It can be described as the diffusion of absorbed gas molecules through the gas separation membrane. The absorbed gas molecules are driven by the concentration gradient between the upstream and 
downstream in the polymer matrix. ${ }^{18}$ The solution diffusion model for the gas transport through an asymmetric membrane occurs in three stages. Firstly, the transported gas is dissolved in the high-pressure face of the polymer, then it is diffused through the polymer, and finally the gas desorbs form the low-pressure side of the polymer. ${ }^{19}$ Figure 2 represents the solution diffusion stages. ${ }^{19}$

\section{MEMBRANE}

DIFFUSION

PERMEATE VAPOUR

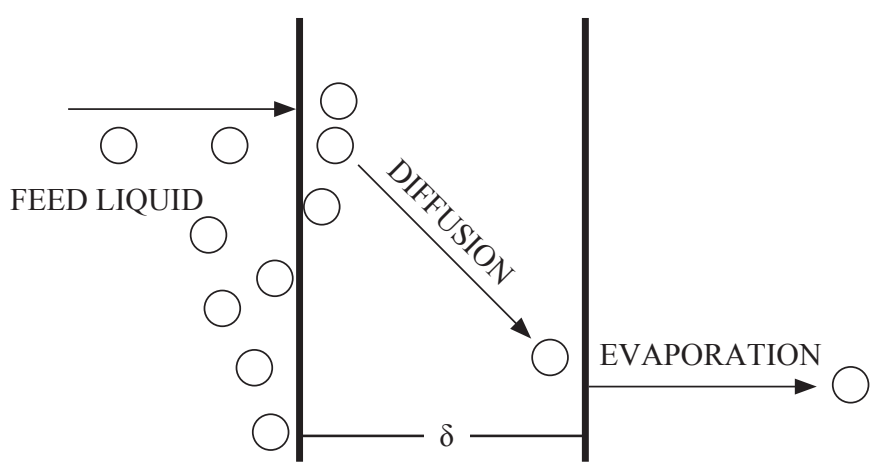

Figure 2: Solution diffusion stages.

The relationship between permeability and solubility can be represented by the following equation: ${ }^{20}$

$$
P_{i}=\mathrm{S} \times \mathrm{D}
$$

where $\mathrm{S}$ is the solubility and $\mathrm{D}$ is the diffusivity.

\subsection{Membrane Characterisation}

\subsubsection{SEM}

Scanning electron microscopy (SEM, Hitachi TM3000, Tokyo) was utilised in the research study to determine the membrane cross-sectional structure and surface morphology. The procedures to perform the SEM were started by immersing the membrane sample into liquid nitrogen in order to prevent the deformation of the membrane structure when the membrane was being separated into small pieces. Then, the membrane-separated samples were coated with platinum to protect them from producing inconsistent images prior to the microscopic observation. 


\subsubsection{ATR-FTIR}

The attenuated total reflectance-Fourier transform infrared spectroscopy (ATRFTIR) was used to investigate the incorporating of the MWCNTs-F into the MMM. The Nicolet IS10 (United States) spectrometer ranging from 4000 to $400 \mathrm{~cm}^{-1}$ was used for the analysis. Each sample was collected with 32 scans at a resolution of $4 \mathrm{~cm}^{-1}$ setting through the diamond crystal. Prior to collecting the samples spectra wave number, the background information of the room condition was obtained first and was repeated three times for each sample.

\section{RESULTS AND DISCUSSION}

\subsection{The Integration of MWCNTs within the CAB Polymer Structure}

\subsubsection{Surface morphology and cross-sectional structure analysis of CAB-M, MMM-P and MMM-F}

Figure 3 illustrates the surface morphology and cross-sectional thickness for cellulose acetate butyrate (CAB-M) and for pristine and functionalised mixed matrix membranes (MMM-P and MMM-0.1F) synthesised from CAB polymer and MWCNTs-P or MWCNTs-F. Based on Figure 3(a), a smooth surface was observed for CAB-M. When the MWCNTs-P were integrated within the CAB polymeric matrix, some clusters were formed on the surface of the membrane, as shown in Figure 3(c). The formed clusters on the membrane surface were due to the changes in the membrane's phase separation kinetics and long-term dope stability caused by the incorporation of the MWCNTs-P into the CAB. ${ }^{17}$ The longterm stability of the dope refers to the ability of the MWCNTs-P particles to remain in a homogeneous dispersion in the solution. This ability depends on the rate of settling of the MWCNTs-P particles and the compatibility of the MWCNTs-P surface with the remaining components of the solution. ${ }^{21}$ In addition, the formation of clusters occurred due to the high amount of MWCNTs-P added to the polymeric matrix as well as the van der Waals forces..$^{22}$ It was further observed that, when the MWCNTs-F were integrated into the polymeric membrane (CAB-M), the surface of the MMM- $0.1 \mathrm{~F}$ became smooth with less clusters formation compared to the MMM-P, as presented in Figure 3(e). This was due to the macromolecular densification of the MWCNTs-F which gives the ability to overcome the buildup of agglomerated structures and clusters on the surface of the membrane. ${ }^{13}$ Moreover, the $\beta$-Cyclodextrin used to functionalise the MWCNTs reduced the effect of van der Waals forces, thus minimising the formation of clusters on the MMM-0.1F surface. ${ }^{23}$ Furthermore, the cross-sectional morphology in Figure 3(b and d) shows that the membrane thickness of the neat CAB-M reduced 

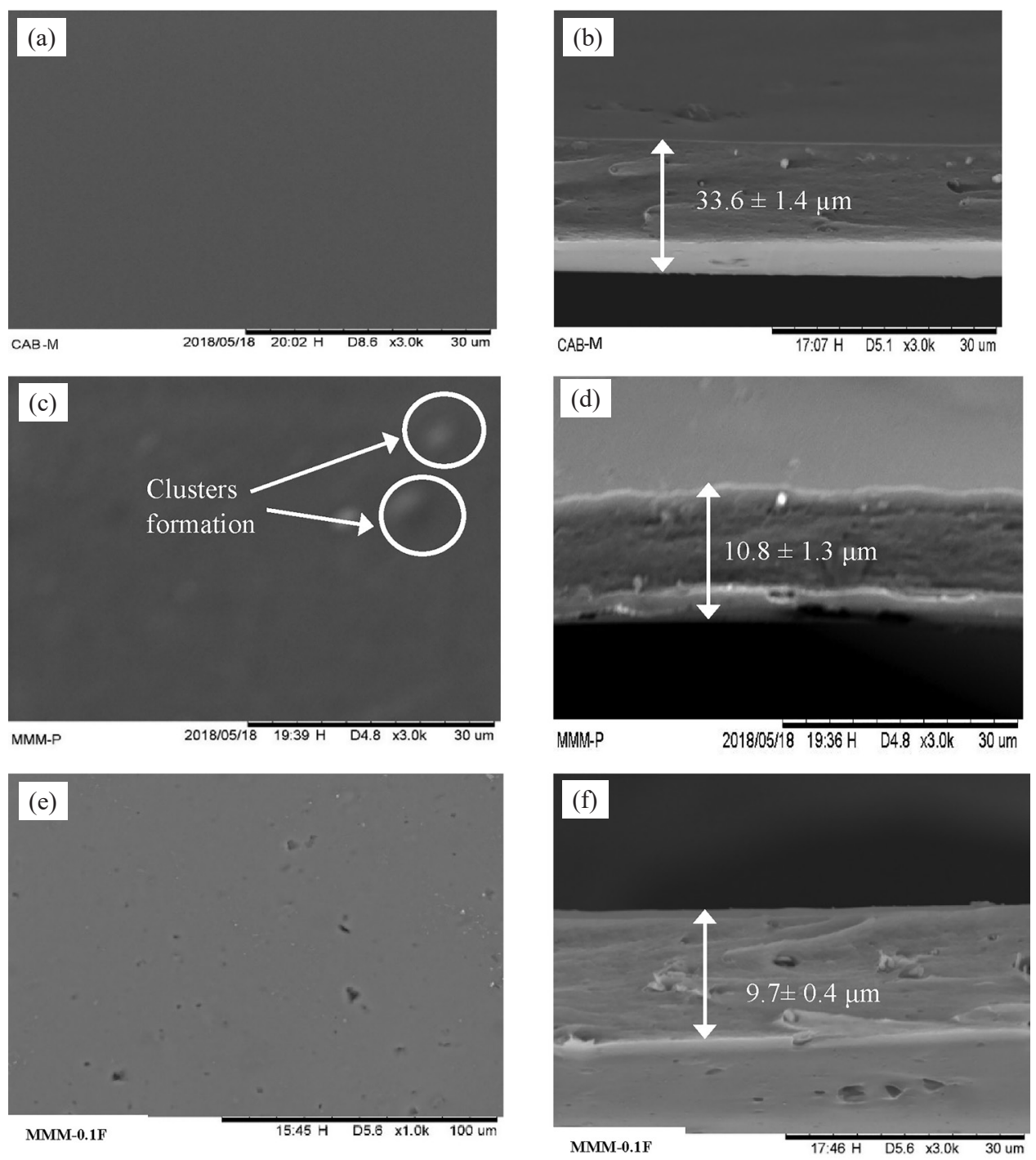

Figure 3: SEM surface and cross-sectional morphologies of the membrane for ( $a$ and $b$ ) CAB-M, (c and d) MMM-P, and (e and f) MMM-0.1F.

from $33.6 \pm 1.4 \mu \mathrm{m}$ to $10.8 \pm 1.3 \mu \mathrm{m}$ when the MWCNTs-P were integrated into the $\mathrm{CAB}$ polymer to form the MMM-P. This reduction in the membrane thickness was due to the change in the polymer chain packing caused by the incorporation of the MWCNTs-P. ${ }^{24}$ The thickness of the MMM became slightly thinner than the MMM-P when the MWCNTs-F were added to the CAB polymer matrix with a thickness of $9.7 \pm 0.4 \mu \mathrm{m}$. This is shown in Figure 3(f) where the thickness of the membrane has a direct impact on the gas separation performance. 
Therefore, a thinner membrane thickness is most preferred for gas separation application as less flow resistance is exerted on the membrane, resulting in a higher permeance rate. ${ }^{13}$

The increase in membrane permeance performance can clearly be seen in Figure 4, where the $\mathrm{CO}_{2}$ permeance for the MMM-P is slightly higher than the permeance of the neat CAB-M, due to the compact thinner layer of MMM-P. However, the closed performance between MMM-P and CAB-M might be due to the agglomerated surface of the MMM-P, which affected its performance. ${ }^{25}$ Meanwhile, the $\mathrm{CO}_{2}$ permeance of MMM-0.1F was significantly higher (19.4 $\pm 0.1 \mathrm{GPU})$ as compared to MMM-P (3.3 $\pm 0.1 \mathrm{GPU})$. This was due to the thin structure of MMM-0.1F in addition to its ability to form channels within the membrane surface which facilitate the transportation of gas molecules through the membrane. ${ }^{26}$ Further to that, the $\beta-C D$ used in the functionalised MWCNTs was the main reason for this superior $\mathrm{CO}_{2}$ permeance performance of MMM- $0.1 \mathrm{~F}$ when compared to MMM-P as it improves the solubility and homogeneous dispersion of CNTs in the MMM. ${ }^{13}$

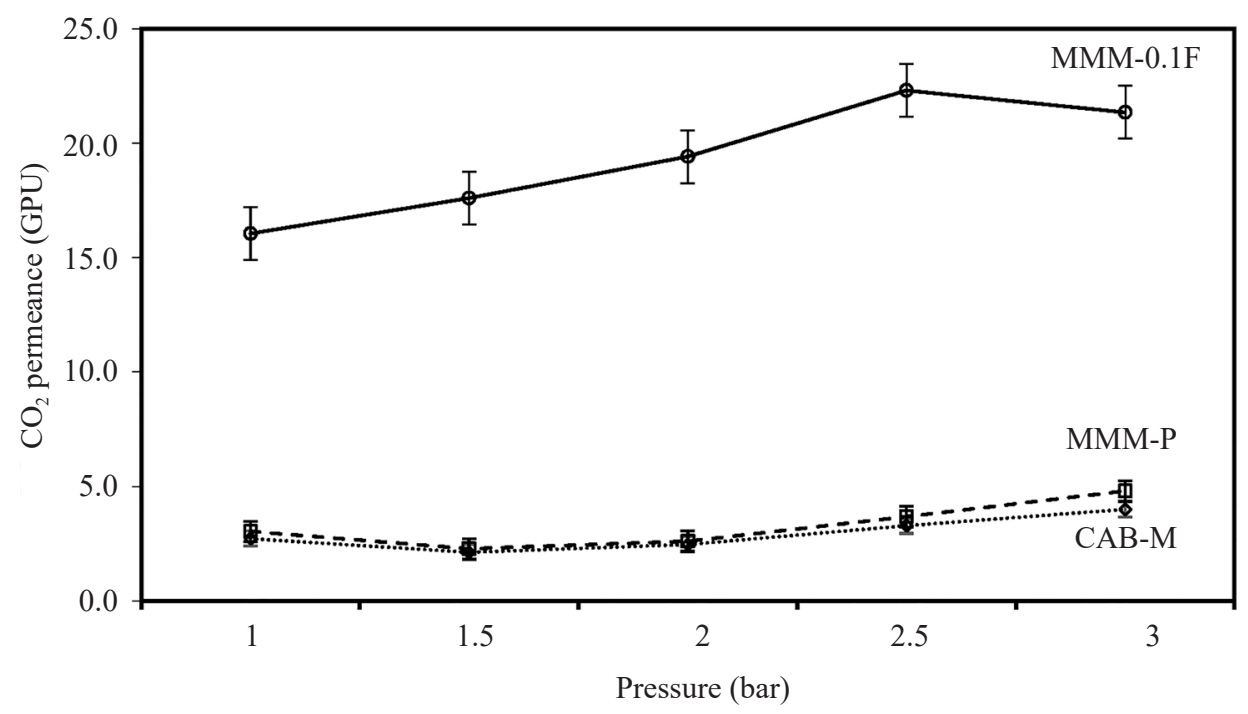

Figure 4: Permeance of $\mathrm{CO}_{2}$ for CAB-M, MMM-P and MMM-0.1F.

These results were further confirmed by the ATR-FTIR, as shown in Figure 5. The transmitting bands at $2900 \mathrm{~cm}^{-1}, 1800 \mathrm{~cm}^{-1}$ and $1460 \mathrm{~cm}^{-1}$ were attributed to the $\mathrm{C}-\mathrm{H}$ stretching, carbonyl group of carboxylic acid $(\mathrm{C}=\mathrm{O})$, and the hydroxyl group $(-\mathrm{OH})$, respectively. ${ }^{27}$ Meanwhile, the bands at $1300 \mathrm{~cm}^{-1}$ and $1030 \mathrm{~cm}^{-1}$ were represented by the acrylate group stretching $(\mathrm{C}-\mathrm{O})$ and the $(\mathrm{C}-\mathrm{O}-\mathrm{C})$ stretching group. ${ }^{28}$ Thus, it is clearly observed that the functional groups of MMM-P and MMM-0.1F are higher than CAB-M. This is because of the aromatic-carbon 
rings found in the MWCNTs and the hydroxyl group (-OH) existing in the betacyclodextrin that was added to functionalise the MWCNTs. ${ }^{24}$

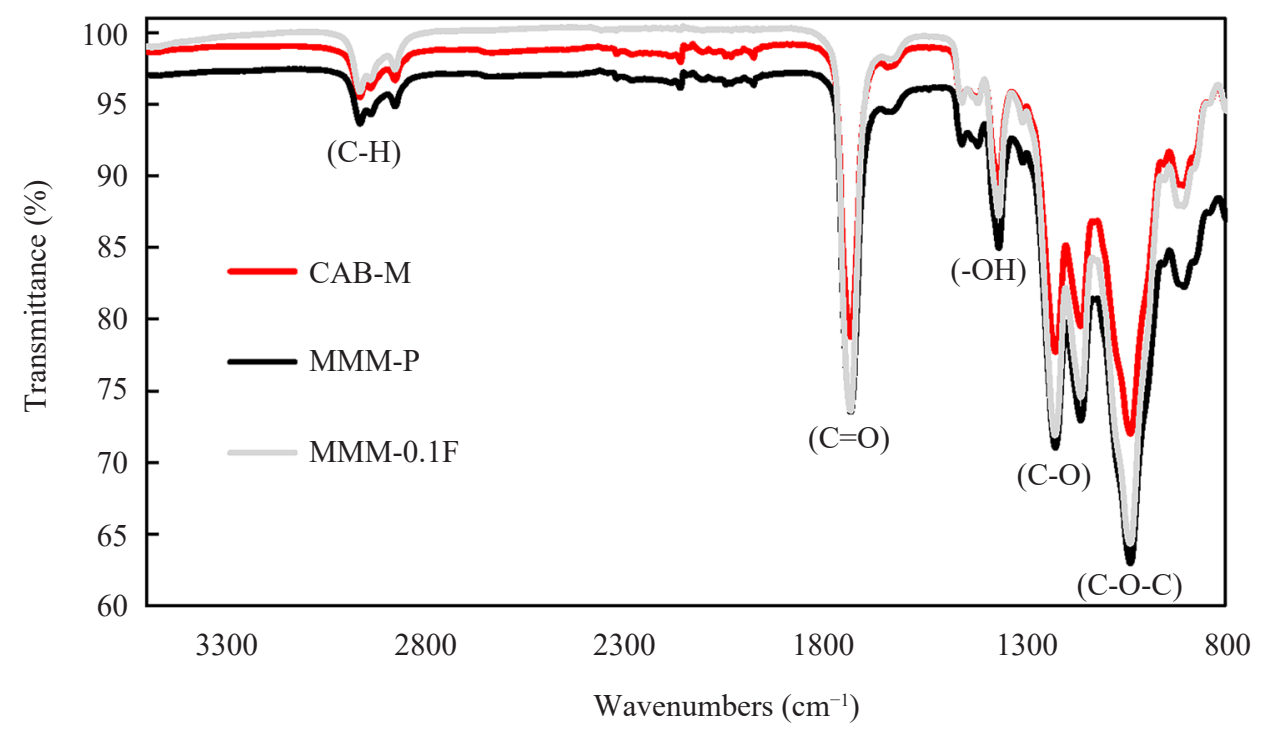

Figure 5: The ATR-FTIR spectroscopy for CAB-M, MMM-P and MMM-0.1F membranes (full-coloured illustration is available in the digital version).

The $\mathrm{N}_{2}$ gas permeance of CAB-M, MMM-P and MMM-0.1F is demonstrated in Figure 6. As displayed in Figure 6, the $\mathrm{N}_{2}$ gas permeance of CAB-M, MMM-P and MMM-0.1F were $2.8 \pm 0.1$ GPU, $5.9 \pm 0.1$ GPU and $16.5 \pm 0.3 \mathrm{GPU}$, respectively. The high $\mathrm{N}_{2}$ permeance of MMM- $0.1 \mathrm{~F}$ was due to its thin compact structure. ${ }^{15}$

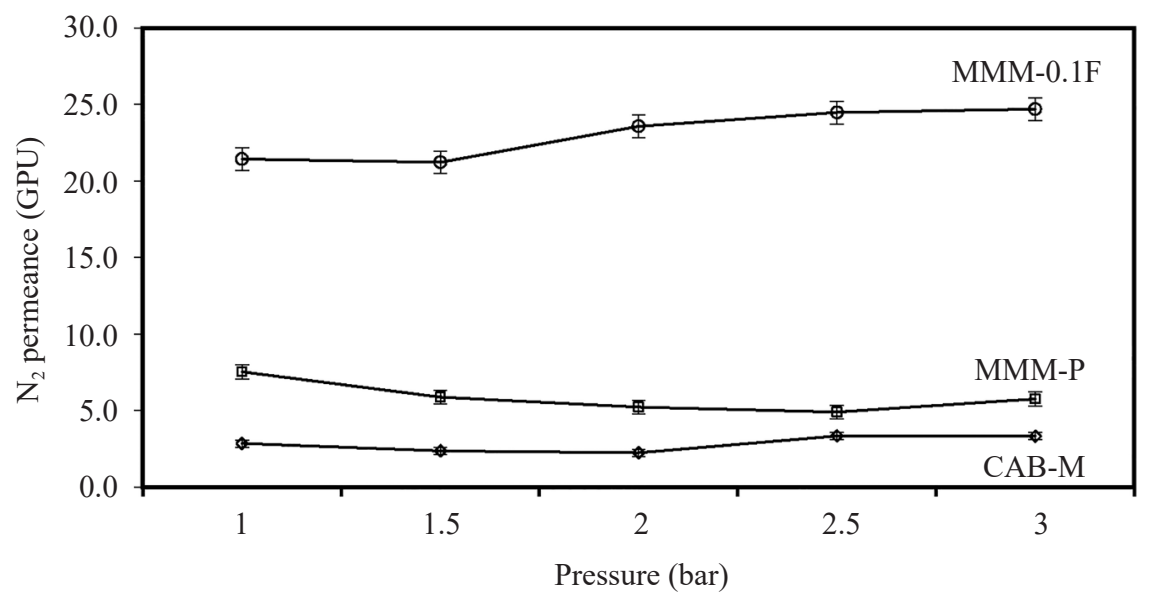

Figure 6: Permeance of $\mathrm{N}_{2}$ for CAB-M, MMM-P and MMM-0.1F. 
The $\mathrm{CO}_{2} / \mathrm{N}_{2}$ selectivity performance of CAB-M, MMM-P and MMM-0.1F is shown in Figure 7. As demonstrated in Figure 7, the CAB-M tends to have a higher $\mathrm{CO}_{2} / \mathrm{N}_{2}$ selectivity $(1.1 \pm 0.1)$ when compared to MMM-P $(0.6 \pm 0.1)$ and MMM$0.1 \mathrm{~F}(0.8 \pm 0.1)$. This might be due to the agglomerated MWCNTs-P and the uncontrolled loadings of MWCNTs-F. ${ }^{25}$ Thus, the loadings of MWCNTs within the $\mathrm{CAB}$ polymer structure will be investigated.

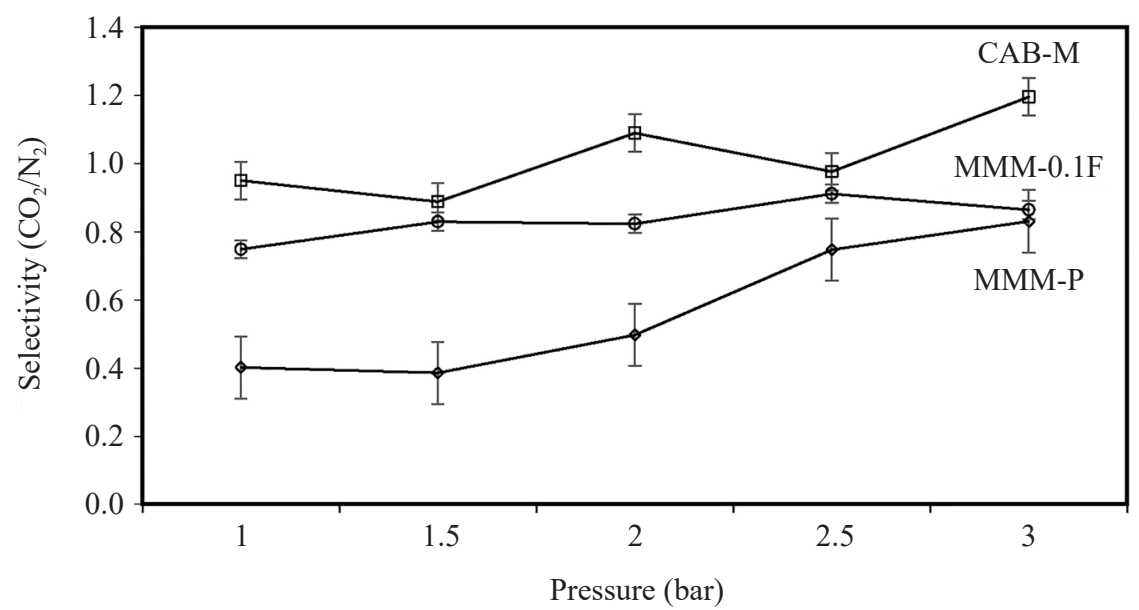

Figure 7: Selectivity of $\mathrm{CO}_{2} / \mathrm{N}_{2}$ gas performance for CAB-M, MMM-P and MMM-0.1F.

\subsection{Effect of Loadings on the CAB/MWCNTs MMM}

\subsubsection{MMM cross-sectional structure and surface morphology analysis}

The effect of different loadings of the MWCNTs-F on the CAB membrane structure was studied, as illustrated in Figure 8. Based on Figure 8(a and c), a smooth surface was formed for MMM-0.0125F and MMM-0.025F. This was due to the strong adhesion between the $\mathrm{CAB}$ and MWCNTs which resulted in an excellent dispersion between the CAB polymer and MWCNTs added. ${ }^{15}$

The formation of white clusters on the surface of the membrane tends to become clearer and more distributed when the content of the MWCNTs increased from $0.1 \mathrm{wt} \%$ to $0.2 \mathrm{wt} \%$, as illustrated in Figure 9(a and c), respectively. The possible explanation for this phenomenon might be due to the increase in the distributed amounts of MWCNTs within the MMM. It can also be observed that the colour of the membrane layer gradually changed from light grey to dark grey, due to the increase in the filler amounts. ${ }^{29}$ 

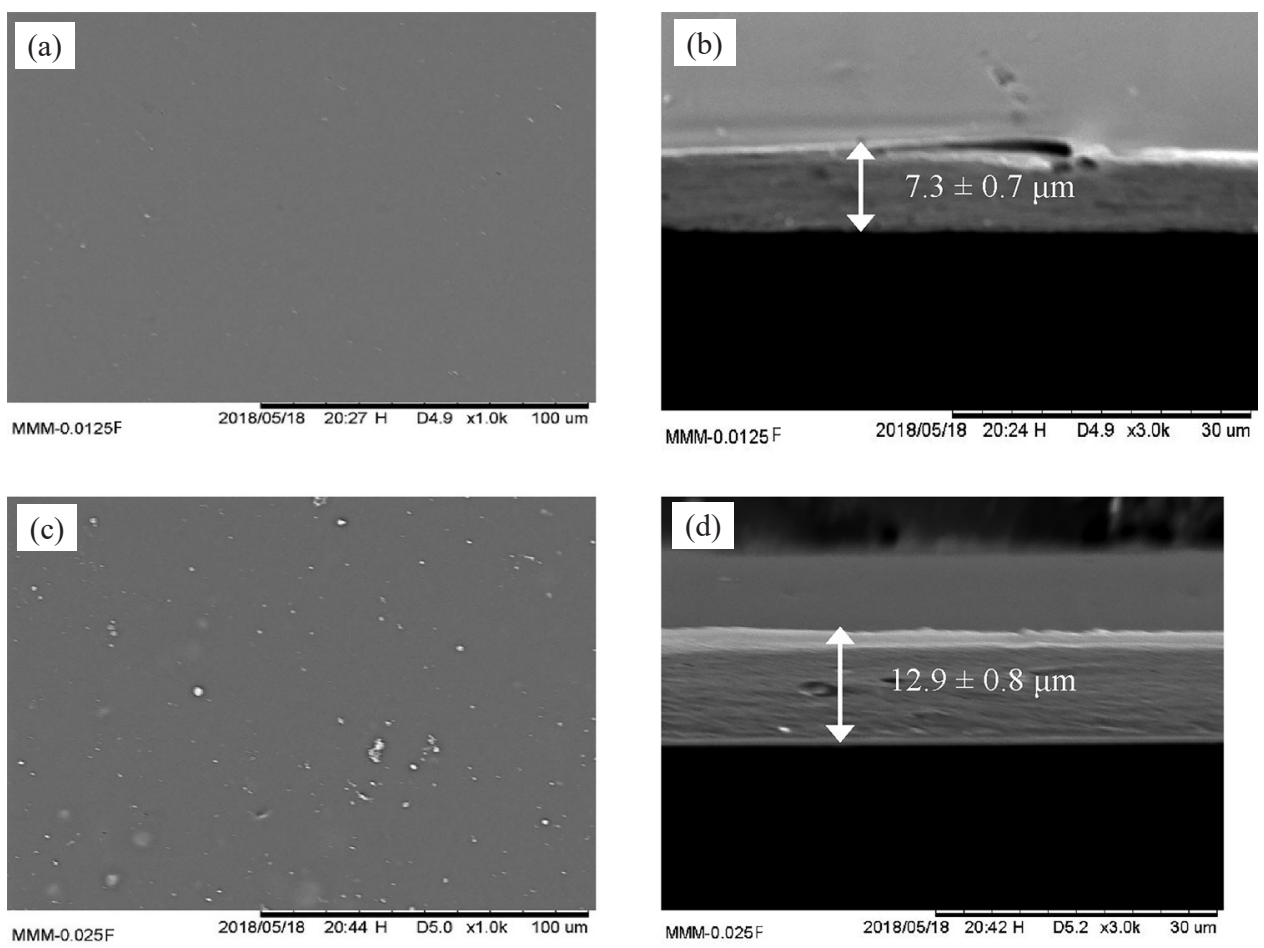

Figure 8: SEM surface and cross-sectional morphologies for (a and b) MMM-0.0125F, and (c and d) for MMM-0.025F.

The formation of dark spots on the surface of the MMM-0.2F in Figure 9(c) was due to the excessive amount of MWCNTs integrating on the CAB polymer which is poorly distributed. ${ }^{29}$

As shown in Figure 8(b and d), the average thickness of the MMM-0.0125F and MMM-0.025F were $7.3 \pm 0.7 \mu \mathrm{m}$ and $12.9 \pm 0.8 \mu \mathrm{m}$, respectively. Meanwhile, the average thickness of the MMM-0.1F and MMM-0.2F were $9.7 \pm 0.4 \mu \mathrm{m}$ and $10.0 \pm 0.1 \mu \mathrm{m}$, as shown in Figure 9(b and d), respectively. Based on Figure 10, it can be seen that when the amount of MWCNTs incorporated into the MMM increases from $0.0125 \mathrm{wt} \%$ to $0.025 \mathrm{wt} \%$ the thickness of the MMM increased to $12.9 \pm 0.8 \mu \mathrm{m}$.

When the content of the MWCNTs increased from $0.1 \mathrm{wt} \%$ to $0.2 \mathrm{wt} \%$, the MMM thickness reduced to $10.0 \pm 0.1 \mu \mathrm{m}$. The possible explanation for that is due to the agglomeration caused by the increase in the MWCNTs content, which weakened the van der Waals forces. ${ }^{13}$ 

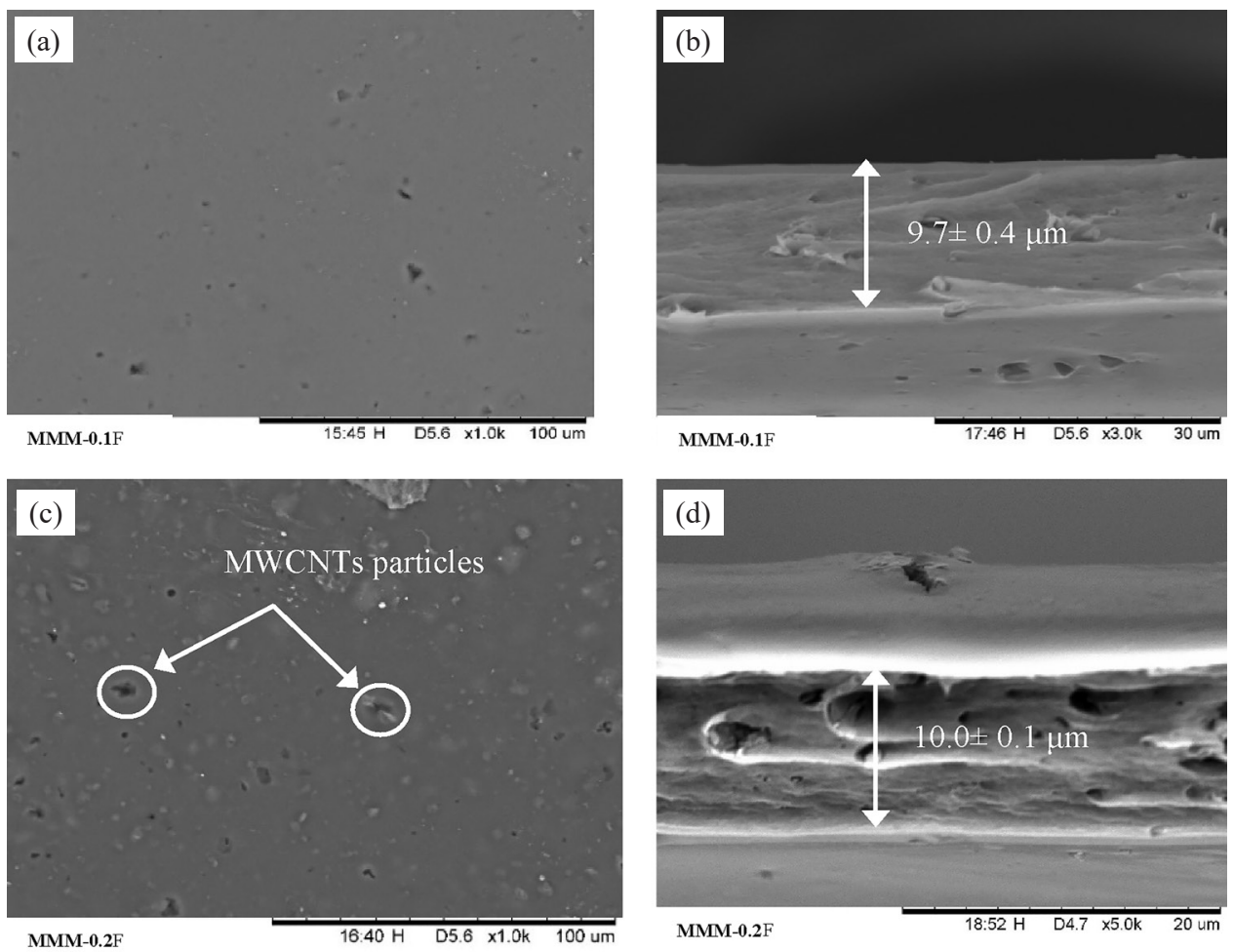

Figure 9: SEM surface and cross-sectional morphologies for ( $\mathrm{a}$ and $\mathrm{b}$ ) MMM-0.1F, and (c and d) for MMM-0.2F.

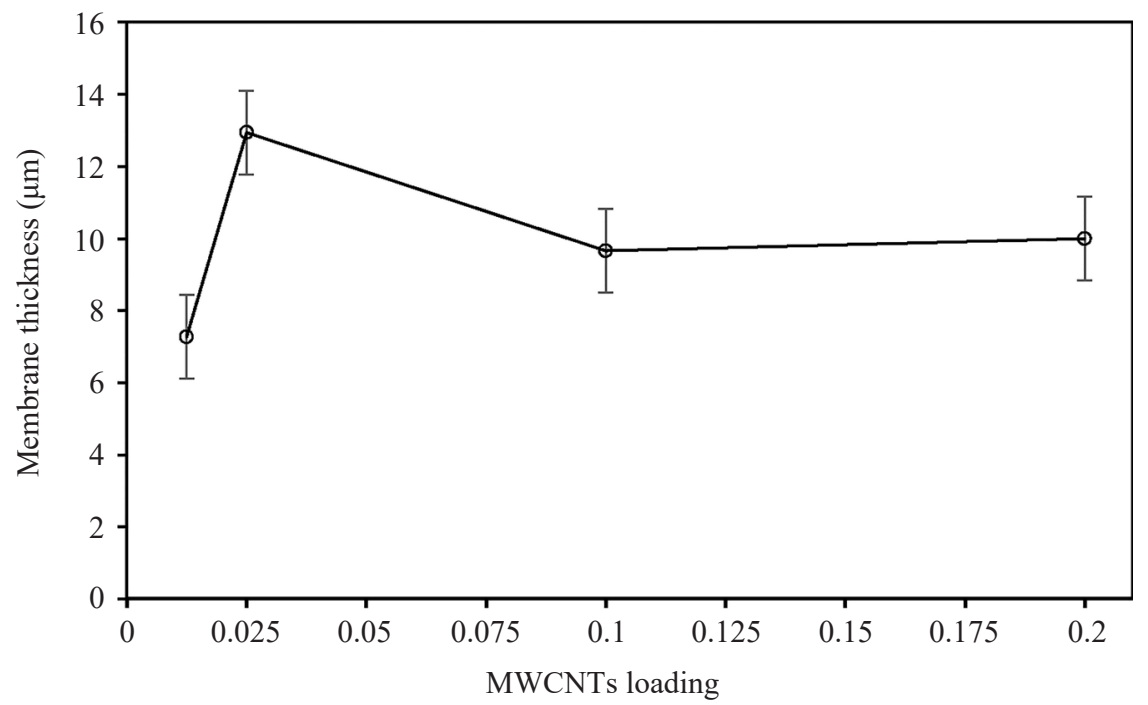

Figure 10: The effect of MWCNTs-F loading on MMM thickness. 


\subsection{Gas Separation Performance}

\subsubsection{Gas separation performance towards $\mathrm{CO}_{2}$ and $\mathrm{N}_{2}$ gases against MWCNTs loadings}

The performance of MMM synthesised at $0.0125 \mathrm{wt} \%, 0.025 \mathrm{wt} \%, 0.1 \mathrm{wt} \%$ and $0.2 \mathrm{wt} \%$ was evaluated towards $\mathrm{CO}_{2}$ gas. Based on Figure 11, it was observed that the highest $\mathrm{CO}_{2}$ permeance ( $\left.36.0 \pm 0.4 \mathrm{GPU}\right)$ was obtained at MWCNTs loading of $0.025 \mathrm{wt} \%$. As the content of MWCNTs increased from $0.1 \mathrm{wt} \%$ to $0.2 \mathrm{wt} \%$, the $\mathrm{CO}_{2}$ permeance of the MMM tends to reduce from 19.4 $\pm 0.1 \mathrm{GPU}$ to $16.5 \pm$ $0.3 \mathrm{GPU}$, respectively. This reduction in the $\mathrm{CO}_{2}$ permeance was due to the high content of MWCNTs embedded into the MMM, which increased the density of the membrane, thus reducing the pores sizes making it more difficult for the $\mathrm{CO}_{2}$ gas to diffuse through. ${ }^{13}$

However, the lowest $\mathrm{CO}_{2}$ permeance performance was obtained at MWCNTs content of $0.0125 \mathrm{wt} \%$ at a value of $5.7 \pm 0.1 \mathrm{GPU}$. Despite the low MWCNTs content in the MMM-0.0125F, the membrane tends to give very low permeance results. This could be due to the poor distribution of the MWCNTs embedded in the $\mathrm{CAB}$ as the content of the MWCNTs was low. ${ }^{17}$

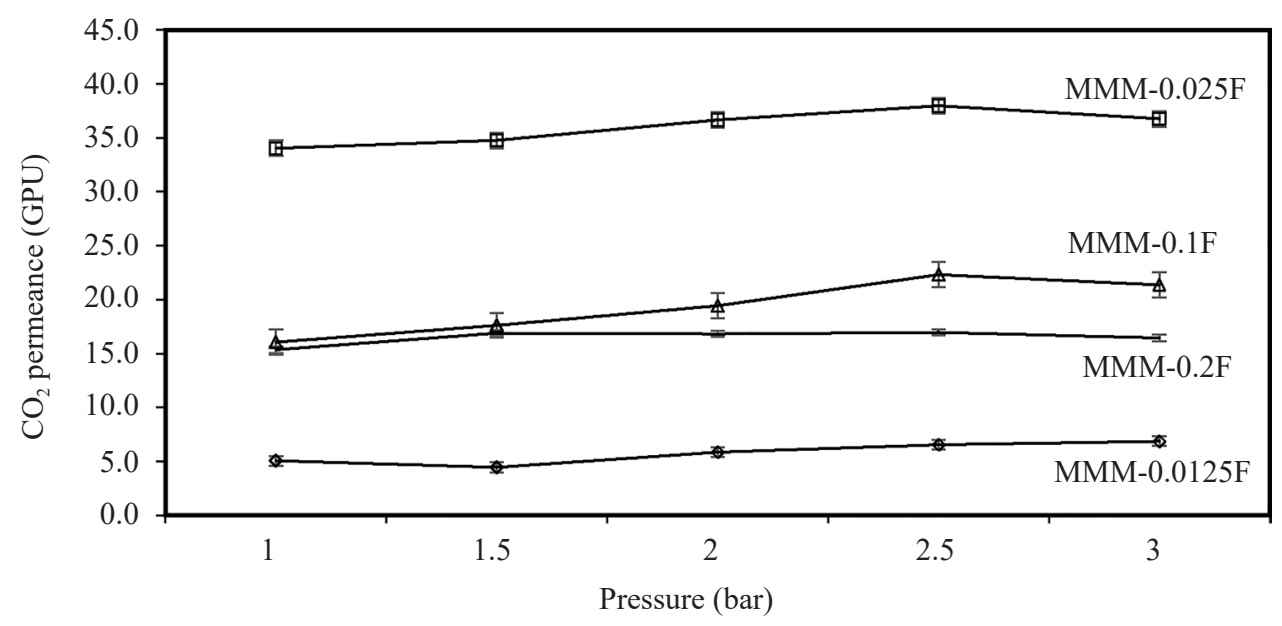

Figure 11: Permeance of $\mathrm{CO}_{2}$ of MMMs prepared at different loadings of MWCNTs-F.

The gas separation performance test was conducted towards the $\mathrm{N}_{2}$ gas for the MMMs, as shown in Figure 12. Based on Figure 12, the highest $\mathrm{N}_{2}$ permeance was exhibited for MMM-0.025F at a value of $28.0 \pm 0.2 \mathrm{GPU}$. Meanwhile, the permeance results for MMM-0.1F and MMM- $0.2 \mathrm{~F}$ was slightly lower than 
MMM-0.025F at values of $23.1 \pm 0.3 \mathrm{GPU}$ and $19.2 \pm 0.1 \mathrm{GPU}$, respectively. The reduction in the $\mathrm{N}_{2}$ permeance of MMM-0.1F and MMM-0.2F is due to the increment in the amount of MWCNTs embedded in the MMM. Thus, the $\mathrm{N}_{2}$ molecules did not diffuse effectively within the membrane matrix. However, the lowest $\mathrm{N}_{2}$ permeance result was obtained for MMM-0.0125F at a value of $7.7 \pm$ 0.1 GPU. This was due to the poor distribution of the MWCNTs across the MMM polymer matrix. ${ }^{30}$

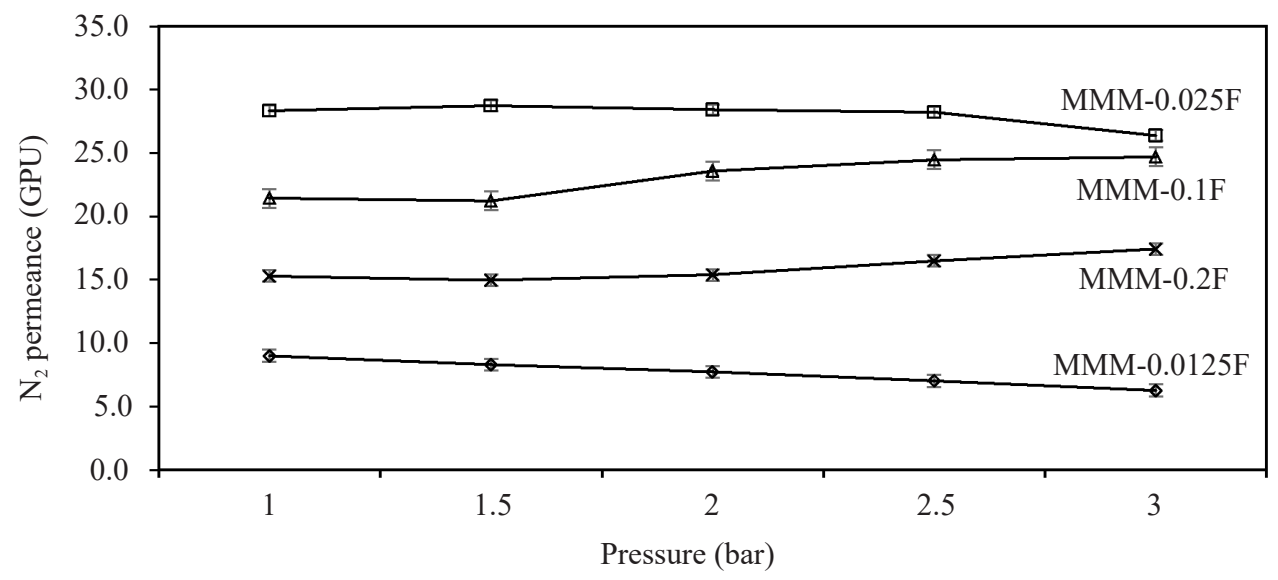

Figure 12: Permeance of $\mathrm{N}_{2}$ of MMMs prepared at different loading of MWCNTs-F.

\subsubsection{Gas separation performance towards selectivity of $\mathrm{CO}_{2} / \mathrm{N}_{2}$ gas against MWCNTs loadings}

The selectivity of the $\mathrm{CO}_{2} / \mathrm{N}_{2}$ gases for the MMMs was investigated and the results are shown in Figure 13. The highest $\mathrm{CO}_{2} / \mathrm{N}_{2}$ selectivity was obtained from MMM-0.025F with an average value of $1.3 \pm 0.1$. By increasing the content of the MWCNTs-F within the CAB polymer matrix from $0.1 \mathrm{wt} \%$ to $0.2 \mathrm{wt} \%$, the selectivity of $\mathrm{CO}_{2} / \mathrm{N}_{2}$ reduced to $0.8 \pm 0.1$. However, MMM-0.0125F proved to have lower $\mathrm{CO}_{2} / \mathrm{N}_{2}$ selectivity at $0.6 \pm 0.3$. This performance could be explained by the ATR-FTIR, as illustrated in Figure 14. It can be observed that as the content of the MWCNTs increases the stretching vibration tends to decrease.

There is high interaction between the polar groups $(-\mathrm{OH}$ and $\mathrm{C}=\mathrm{O})$ in the membrane and non-polar $\mathrm{CO}_{2}$, where the transmittance bands of the polar functional group $(-\mathrm{OH})$ and $(\mathrm{C}=\mathrm{O})$ are the highest for MMM-0.025F. 


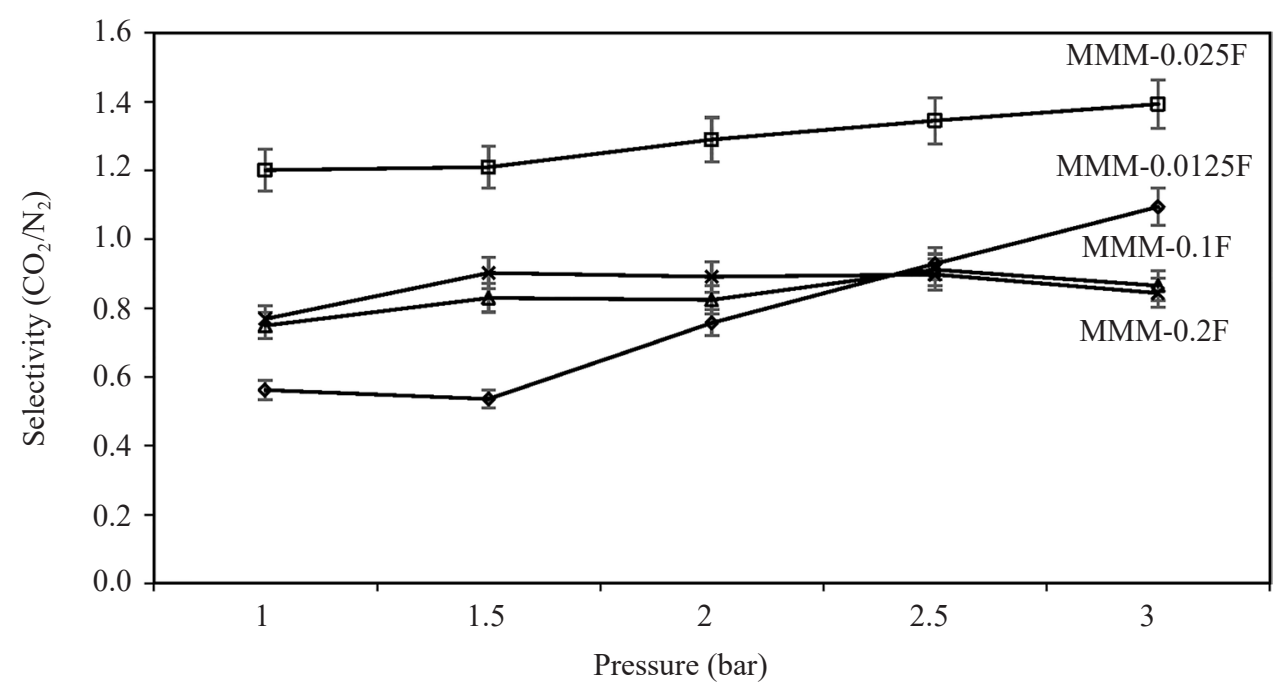

Figure 13: $\mathrm{CO}_{2} / \mathrm{N}_{2}$ selectivity of MMMs prepared at different loadings of MWCNTs-F.

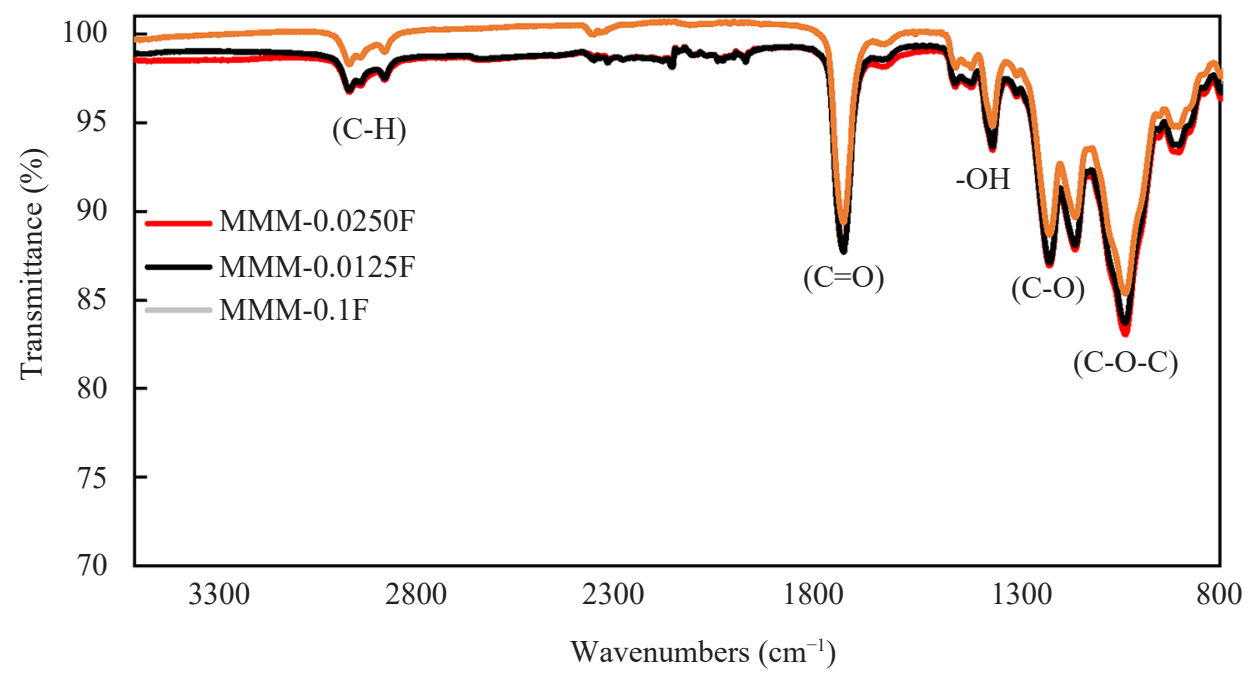

Figure 14: The ATR-FTIR spectroscopy for MMM-0.0125F, MMM-0.025F, MMM-0.1F and MMM-0.2F (full-coloured illustration is available in the digital version).

Furthermore, the effect of MWCNTs loadings on the gas separation performance obtained from the present study were compared to other researches using the polymer/MWCNTs matrix membrane for gas separation as presented in Table 2 . Based on Table 2, it can be clearly observed that the incorporation of different loadings of MWCNTs into three different types of polymer membranes have a 
direct influence on the gas separation performance of the MMM. The incorporation of MWCNTs with filler amount of $0.025 \mathrm{wt} \%$ into the CAB polymer presented in this work has shown a high $\mathrm{CO}_{2}$ permeance in comparison to the literatures. This might be due to the good interaction between the polar functional groups $(\mathrm{C}=\mathrm{O}$ and $\mathrm{O}-\mathrm{H})$ existing in the $\mathrm{CAB}$ polymer with the non-polar $\mathrm{CO}_{2}$ gas which enhanced the $\mathrm{CO}_{2}$ permeance performance of the MMM. ${ }^{24}$

Table 2: A comparison between current study gas separation performance results and other literature works.

\begin{tabular}{|c|c|c|c|c|c|c|c|}
\hline \multirow{2}{*}{ Reference } & \multirow{2}{*}{ Polymer } & \multirow{2}{*}{ Filler } & \multirow{2}{*}{$\begin{array}{l}\text { Filler } \\
\text { amount } \\
\text { (wt\%) }\end{array}$} & \multicolumn{2}{|c|}{ Permeability (Barrer) } & \multirow{2}{*}{$\frac{\text { Selectivity }}{\mathrm{CO}_{2} / \mathrm{N}_{2}}$} & \multirow{2}{*}{$\begin{array}{c}\text { Pressure } \\
\text { (Bar) }\end{array}$} \\
\hline & & & & $\mathrm{CO}_{2}$ & $\mathrm{~N}_{2}$ & & \\
\hline \multirow{4}{*}{$\begin{array}{l}\text { Present } \\
\text { work }\end{array}$} & \multirow[t]{4}{*}{$\mathrm{CAB}$} & \multirow[t]{4}{*}{ MWCNTs } & $0.0 \%$ & 134.4 & 112.2 & 1.2 & \multirow{4}{*}{3} \\
\hline & & & $0.0125 \%$ & $\begin{array}{c}49.6 \\
(-63.1 \%)\end{array}$ & $\begin{array}{c}46.0 \\
(-59.0 \%)\end{array}$ & $\begin{array}{c}1.1 \\
(-8.3 \%)\end{array}$ & \\
\hline & & & $0.025 \%$ & $\begin{array}{c}464.4 \\
(245.5 \%)\end{array}$ & $\begin{array}{c}361.2 \\
(227.3 \%)\end{array}$ & $\begin{array}{c}1.4 \\
(16.6 \%)\end{array}$ & \\
\hline & & & $0.1 \%$ & $\begin{array}{c}207.1 \\
(54.1 \%)\end{array}$ & $\begin{array}{c}239.6 \\
(113.5 \%)\end{array}$ & $\begin{array}{c}0.8 \\
(-33.3 \%)\end{array}$ & \\
\hline \multirow{4}{*}{$\begin{array}{l}\text { Moghadassi } \\
\text { et al. } .^{31}\end{array}$} & \multirow[t]{4}{*}{$\mathrm{CA}$} & \multirow[t]{4}{*}{ MWCNTs } & $0.00 \%$ & 1.1 & 0.4 & 2.4 & \multirow{4}{*}{2} \\
\hline & & & $0.25 \%$ & 3.4 & 0.4 & 7.7 & \\
\hline & & & $0.65 \%$ & 0.6 & 6.4 & 9.3 & \\
\hline & & & $0.1 \%$ & 0.7 & 7.7 & 9.9 & \\
\hline \multirow[t]{2}{*}{ Rao et al. ${ }^{32}$} & \multirow[t]{2}{*}{ Polyetherimide } & \multirow[t]{2}{*}{ MWCNTs } & $0.0 \%$ & 52.6 & 3.0 & 17.5 & \multirow{2}{*}{2} \\
\hline & & & $15.0 \%$ & 1463.0 & 30.0 & 48.8 & \\
\hline \multirow{2}{*}{$\begin{array}{l}\text { Tseng } \\
\text { et al. }{ }^{33}\end{array}$} & \multirow[t]{2}{*}{ Polyimide } & \multirow[t]{2}{*}{ MWCNTs } & $0.0 \%$ & 222.9 & 84.1 & 2.7 & \multirow{2}{*}{2} \\
\hline & & & $15.0 \%$ & 886.6 & 213.2 & 4.1 & \\
\hline \multirow[t]{4}{*}{ Sun et al. ${ }^{34}$} & \multirow[t]{4}{*}{ Polyimide } & \multirow[t]{4}{*}{ MWCNTs } & $0.0 \%$ & 2.3 & 0.15 & 15.4 & \multirow{4}{*}{1} \\
\hline & & & $1.0 \%$ & 4.8 & 0.2 & 26.6 & \\
\hline & & & $2.0 \%$ & 6.7 & 0.2 & 32.2 & \\
\hline & & & $3.0 \%$ & 9.7 & 0.2 & 37.7 & \\
\hline \multirow{2}{*}{$\begin{array}{l}\text { Cong } \\
\text { et al. } .^{35}\end{array}$} & \multirow{2}{*}{$\begin{array}{l}\text { Poly } \\
\text { (2 6-diphenyl- } \\
\text { 1,4-phenylene } \\
\text { oxide) }\end{array}$} & \multirow[t]{2}{*}{ MWCNTs } & $0.0 \%$ & 78.0 & 2.6 & 30.0 & \multirow[b]{2}{*}{0.7} \\
\hline & & & $5.0 \%$ & 134.0 & 4.0 & 34.0 & \\
\hline
\end{tabular}

Notes: The percentage increase or decrease is relative to the CAB with $0.0 \%$ MWCNTs filler amount 


\section{CONCLUSION}

In this study, a new MMM was prepared by incorporating $\mathrm{CAB}$ at different molecular weights of 12000, 65000 and 70000 with MWCNTs. The separation performance of the MMM was evaluated towards $\mathrm{CO}_{2}$ and $\mathrm{N}_{2}$. As far as the development of MMMs is concern, it was proven that the MMM has a higher $\mathrm{CO}_{2} / \mathrm{N}_{2}$ permeance rate and selectivity as compared to the neat CAB-M. Thus, different loadings of the functionalised MWCNTs were embedded into the $\mathrm{CAB}$ polymer matrix and the optimal loading was found to be at $0.025 \mathrm{wt} \%$ (MMM$0.025 \mathrm{~F}$ ). The $\mathrm{CO}_{2}$ permeance and $\mathrm{CO}_{2} / \mathrm{N}_{2}$ selectivity of MMM- $0.025 \mathrm{~F}$ were $36.0 \pm 0.4 \mathrm{GPU}$ and $1.3 \pm 0.1 \mathrm{GPU}$, respectively. Based on these results, the MMM- $0.025 \mathrm{~F}$ was able to demonstrate an increment of $245.5 \%$ for $\mathrm{CO}_{2}$ permeance and $16.6 \%$ for $\mathrm{CO}_{2} / \mathrm{N}_{2}$ selectivity as compared to the pure CAB-M. In summary, the different loadings of MWCNTs can affect and influence the membrane surface and gas permeation characteristics of the membrane.

\section{ACKNOWLEDGEMENTS}

The authors acknowledge the Ministry of Higher Education Malaysia (MOHE) for providing the Fundamental Research Grand Scheme (FRGS) (FRGS/1/2015/ TK02/CURTIN/03/01) and Cost Centre 001048. We would also like to thank Long-term Research Grant Scheme (LRGS), Universiti Sains Malaysia (304/ PJKIMIA/6050296/U124) and Curtin Cost Centre 001047.

\section{REFERENCES}

1. Brunetti, A. et al. (2010). Membrane technologies for $\mathrm{CO}_{2}$ separation. J. Membr. Sci., 359(1), 115-125. https://doi.org/10.1016/j.memsci.2009.11.040

2. Zhao, L. et al. (2008). A parametric study of $\mathrm{CO}_{2} / \mathrm{N}_{2}$ gas separation membrane processes for post-combustion capture. J. Membr. Sci., 325(1), 284-294. https://doi.org/10.1016/j.memsci.2008.07.058

3. Baker, R. (2001). Future directions of membrane gas-separation technology. Membr. Technol., 138, 5-10. https://doi.org/10.1016/S0958-2118(01)80332-3

4. Lee, R. J. et al. (2016). Improvement of $\mathrm{CO}_{2} / \mathrm{N}_{2}$ separation performance by polymer matrix cellulose acetate butyrate. IOP Conf. Ser. Mater. Sci. Eng., 206, 1-9. https://doi.org/10.1088/1757-899X/206/1/012072

5. Shen, Y. \& Lua, A. C. (2012). Preparation and characterization of mixed matrix membranes based on poly(vinylidene fluoride) and zeolite 4A for gas separation. Polym. Eng. Sci., 52(10), 2106-2113. https://doi.org/10.1002/pen.23165 
6. Hamm, J. B. S. et al. (2017). Recent advances in the development of supported carbon membranes for gas separation. Int. J. Hydr. Energy, 42(39), 24830-24845. https://doi.org/10.1016/j.ijhydene.2017.08.071

7. Nejad, M. N. \& Asghari, M. (2016). Investigation of carbon nanotubes in mixed matrix membranes for gas separation: A review. Chem. Bio. Eng. Rev., 3(6), 276-298. https://doi.org/10.1002/cben.201600012

8. Dechnik, J. et al. (2017). Mixed-matrix membranes. Angew. Chem. Int. Ed., 56(32), 9292-9310. https://doi.org/10.1002/anie.201701109

9. Murali, R. S. et al. (2010). Gas permeation behavior of Pebax-1657 nanocomposite membrane incorporated with multiwalled carbon nanotubes. Ind. Eng. Chem. Res., 49(14), 6530-6538. https://pubs.acs.org/doi/abs/10.1021/ie9016495

10. Ye, F., Zhang, J. M. \& Zhang, J. (2015). Gas separation properties of cellulose acetate butyrate/MWCNTs mixed matrix membranes. Acta Polym. Sin., 12, 13961401. https://doi.org/10.11777/j.issn1000-3304.2015.15095

11. Mina, U. et al. (2017). Effect of elevated temperature and carbon dioxide on maize genotypes health index. Ecol. Ind., 105, 292-302. https://doi.org/10.1016/j. ecolind.2017.08.060

12. Chen, J., Dyer, M. J. \& Yu, M. F. (2001). Cyclodextrin-mediated soft cutting of single-walled carbon nanotubes. J. Am. Chem. Soc., 123(25), 6201-6202. https://pubs.acs.org/doi/10.1021/ja015766t

13. Ahmad, A. L. et al. (2014). A cellulose acetate/multi-walled carbon nanotube mixed matrix membrane for $\mathrm{CO}_{2} / \mathrm{N}_{2}$ separation. J. Membr. Sci., 451, 55-66. https://doi.org/10.1016/j.memsci.2013.09.043

14. Jiang, L. Y., Chung, T. S. \& Kulprathipanja, S. (2006). An investigation to revitalize the separation performance of hollow fibers with a thin mixed matrix composite skin for gas separation. J. Membr. Sci., 276(1), 113-125. https://doi.org/10.1016/j. memsci.2005.09.041

15. Aroon, M. A. et al. (2010). Performance studies of mixed matrix membranes for gas separation: A review. Sep. Purif. Technol., 75(3), 229-242. https://doi. org/10.1016/j.seppur.2010.08.023

16. Liu, K. et al. (2008). Assembly of $\beta$-cyclodextrins acting as molecular bricks onto multiwall carbon nanotubes. J. Am. Chem. Soc., 112(4), 951-957. https://pubs.acs. org/doi/10.1021/jp0756754

17. Ismail, A. F. et al. (2011). Gas separation performance of polyethersulfone/multiwalled carbon nanotubes mixed matrix membranes. Sep. Purif. Technol., 80(1), 20-31. https://doi.org/10.1016/j.seppur.2011.03.031

18. George, S. C. \& Thomas, S. (2001). Transport phenomena through polymeric systems. Prog. Polym. Sci., 26(6), 985-1017. https://doi.org/10.1016/S00796700(00)00036-8

19. Wijmans, J. G. \& Baker, R. W. (1995). The solution-diffusion model: A review. J. Membr. Sci., 107(1), 1-21. https://doi.org/10.1016/0376-7388(95)00102-I

20. Yu, B., Cong, H. \& Zhao, X. (2012). Hybrid brominated sulfonated poly(2,6diphenyl-1,4-phenylene oxide) and $\mathrm{SiO}_{2}$ nanocomposite membranes for $\mathrm{CO}_{2} /$ $\mathrm{N}_{2}$ separation. Prog. Nat. Sci., 22(6), 661-667. https://doi.org/10.1016/j. pnsc.2012.11.004 
21. Husain, S. \& Koros, W. J. (2007). Mixed matrix hollow fiber membranes made with modified HSSZ-13 zeolite in polyetherimide polymer matrix for gas separation. J. Membr. Sci., 288(1), 195-207. https://doi.org/10.1016/j.memsci.2006.11.016

22. Sahoo, N. G. et al. (2010). Polymer nanocomposites based on functionalized carbon nanotubes. Prog. Polym. Sci., 35(7), 837-867. https://doi.org/10.1016/j. progpolymsci.2010.03.002

23. Sanip, S. M. et al. (2011). Gas separation properties of functionalized carbon nanotubes mixed matrix membranes. Sep. Purif. Technol., 78(2), 208-213. https://doi.org/10.1016/j.seppur.2011.02.003

24. Lee, R. J. et al. (2018). Incorporation of functionalized multi-walled carbon nanotubes (MWCNTs) into cellulose acetate butyrate (CAB) polymeric matrix to improve the $\mathrm{CO}_{2} / \mathrm{N}_{2}$ separation. Process. Saf. Environ., 117, 159-167. https://doi. org/10.1016/j.psep.2018.04.021

25. Puleo, A. C., Paul, D. R. \& Kelley, S. S. (1989). The effect of degree of acetylation on gas sorption and transport behavior in cellulose acetate. J. Membr. Sci., 47(3), 301-332. https://doi.org/10.1016/S0376-7388(00)83083-5

26. Mustafa, A. et al. (2010). The effect of functionalization carbon nanotubes (CNTs) on the performance of PES-CNTs mixed matrix membrane. Int. J. Sci. Eng., 1(1), $15-20$.

27. Lavorgna, M. et al. (2013). Silanization and silica enrichment of multiwalled carbon nanotubes: Synergistic effects on the thermal-mechanical properties of epoxy nanocomposites. Eur. Polym. J., 49(2), 428-438. https://doi.org/10.1016/j. eurpolymj.2012.10.003

28. Lou, Y. et al. (2014). A facile way to prepare ceramic-supported graphene oxide composite membrane via silane-graft modification. Appl. Surf. Sci., 307, 631-637. https://doi.org/10.1016/j.apsusc.2014.04.088

29. Farahani, M. H. D. A., Hua, D. \& Chung, T. S. (2018). Cross-linked mixed matrix membranes (MMMs) consisting of amine-functionalized multi-walled carbon nanotubes and P84 polyimide for organic solvent nanofiltration (OSN) with enhanced flux. J. Membr. Sci., 548, 319-331. https://doi.org/10.1016/j. memsci.2017.11.037

30. Aghaei, Z. et al. (2018). The influence of fumed silica content and particle size in poly (amide 6-b-ethylene oxide) mixed matrix membranes for gas separation. Sep. Purif. Technol., 199, 47-56. https://doi.org/10.1016/j.seppur.2018.01.035

31. Moghadassi, A. R. et al. (2014). Fabrication and modification of cellulose acetate based mixed matrix membrane: Gas separation and physical properties. J. Ind. Eng. Chem., 20(3), 1050-1060. https://doi.org/10.1016/j.jiec.2013.06.042

32. Rao, P. S. et al. (2008). A comparison of carbon/nanotube molecular sieve membranes with polymer blend carbon molecular sieve membranes for the gas permeation application. Microp. Mesop. Mat., 113(1), 499-510. https://doi. org/10.1016/j.micromeso.2007.12.008

33. Tseng, H. H. et al. (2009). Preparation and characterization of carbon molecular sieve membranes for gas separation-The effect of incorporated multi-wall carbon nanotubes. Desalin., 240(1), 40-45. https://doi.org/10.1016/j.desal.2008.01.048 
34. Sun, H. et al. (2017). Fabrication of polyimide and functionalized multi-walled carbon nanotubes mixed matrix membranes by in-situ polymerization for $\mathrm{CO}_{2}$ separation. Sep. Purif. Technol., 177, 327-336. https://doi.org/10.1016/j. seppur.2017.01.015

35. Cong, H. et al. (2007). Carbon nanotube composite membranes of brominated poly(2,6-diphenyl-1,4-phenylene oxide) for gas separation. J. Membr. Sci., 294(1), 178-185. https://doi.org/10.1016/j.memsci.2007.02.035 